A morte no centro da vida: reflexões sobre a cura e a não-cura nas reduções jesuítico-guaranis (1609-75)

\section{Death in the center of} life: reflections on curing and non-curing in Jesuit-Guarani

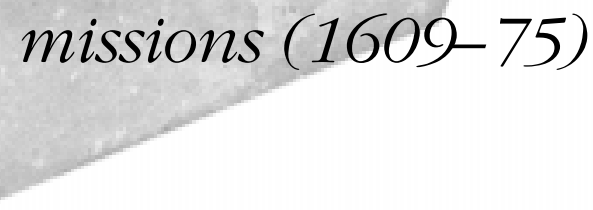

Eliane Cristina Deckmann Fleck

Professora de história da Unisinos, RS Travessa Iracema, 461 Bairro Jardim América 93032-190 São Leopoldo - RS Brasil ecdfleck@terra.com.br
FLECK, E. C. D.: 'A morte no centro da vida: reflexões sobre a cura e a não-cura nas reduções jesuítico-guaranis (1609-75)'. História, Ciências, Saúde-Manguinhos, vol. 11(3): 635-60, set.-dez. 2004.

O tema deste artigo é o impacto das concepções cristãs ocidentais acerca da doença e da morte sobre a sensibilidade indígena guarani e sua tradução, em termos de representações e práticas sociais, nas reduções jesuítico-guaranis circunscritas à Província Jesuítica do Paraguai, no século XVII. A investigação baseia-se em uma releitura das Cartas Ânuas da Província Jesuítica do Paraguai, referentes ao período de 1609 a 1675 . Busca-se verificar como as demonstrações próprias da sensibilidade guarani foram, ao longo do período analisado, apropriadas pelo discurso jesuítico, como resultado do processo de conversão ao cristianismo, e também avaliar as transformações observáveis na sensibilidade guarani em decorrência da nova realidade reducional.

PALAVRAS-CHAVE: Guarani, sensibilidade, doença, morte, discurso jesuítico.

FLECK, E. C. D.: 'Death in the center of life: reflections on curing and non-curing in Jesuit-Guarani missions (1609-75)'. História, Ciências, Saúde-Manguinhos, vol. 11(3): 635-60, Sept-Dec. 2004.

The article investigates the impact of Western Christian concepts of disease and death on indigenous Guarani sensibility and their translation into social representations and practices in the Jesuit-Guarani missions of Paraguay's Jesuit Province during the seventeenth century. This research is based on a re-reading of the Cartas Ânuas da Província Jesuitica do Paraguai, which encompass the 1609-75 period. The study seeks to ascertain how expressions of Guarani sensibility were appropriated by Jesuit discourse as part of the process of conversion to Christianity. It also assesses observable changes in Guarani sensibility as a result of this new mission reality.

KEYWORDS: Guarani, sensibility, disease, death, Jesuit discourse. 


\begin{abstract}
${ }^{1} \mathrm{O}$ termo redução (reducción) foi empregado na América em três acepções: em alguns casos, o processo de congregar índios infiéis em povoados; o próprio povoado; $\mathrm{e}$, ainda, o conjunto de povoados considerados unitariamente por razões geográficas ou missionárias.
\end{abstract}

\footnotetext{
${ }^{2}$ A antiga Província do Paraguai abrangia, na época colonial, limites bastante mais extensos que os da moderna República paraguaia. Recebendo o nome do rio que a banhava, compreendia uma imensa região que se estendia entre o Brasil e o Peru, até o rio da Prata e o Oceano Atlântico.
}

\footnotetext{
${ }^{3}$ Em relação às Cartas Ânuas deve-se observar que as Litterae Anuae constituíam a correspondência periódica que os padres provinciais enviavam ao padre geral da Companhia de Jesus. Elas se baseavam nos relatórios anuais que o provincial recebia dos superiores de residências, colégios, universidades e missões junto aos índios. Continham detalhada informação sobre as casas, suas obras, pessoas e atividades. As Cartas Ânuas relativas à Província Jesuítica do Paraguai cobrem o período de 1609 a 1675 e, após um intervalo de cerca de quarenta anos, de 1714 a 1762 .
}

\section{Introdução}

$\mathrm{O}$ tema do presente artigo é o impacto das concepções cristãs ocidentais acerca da doença e da morte na sensibilidade indígena guarani e sua tradução em termos de representações e práticas sociais, nas reduções jesuítico-guaranis ${ }^{1}$ circunscritas à $^{2}$ Província Jesuítica do Paraguai², no século XVII.

A investigação baseia-se numa releitura das Cartas Ânuas da Província Jesuítica do Paraguai ${ }^{3}$, referentes ao período de 1609 a 1675. Busca-se verificar como as demonstrações próprias da sensibilidade guarani foram, ao longo do período analisado, apropriadas pelo discurso jesuítico, como resultado do processo de conversão ao cristianismo; e também avaliar as transformações observáveis na sensibilidade guarani em decorrência da nova realidade reducional.

Os registros contidos nas Cartas Ânuas enfatizam sobretudo os denominados sucessos notáveis ou casos edificantes. Os que se referem às transgressões e incidência dos "vícios abomináveis" são destacados, com a preocupação de relacioná-los às punições divinas que se abatiam sobre os pecadores e às demonstrações de arrependimento que levavam com freqüência à conversão e à mudança de condutas.

As pestes e os períodos de fome ocupam de forma significativa os relatos do período compreendido entre as décadas de 1630 e 1650, pois constituíam as razões potenciais do fracasso da ação missionária entre os guarani. O período oferece os relatos mais ricos em relação a curas, sonhos, visões, mortes e ressurreições aparentes, profundamente marcados por uma atmosfera de exaltação mística decorrente das manifestações de devoção e piedade por parte dos indígenas.

Em sua obra Os reis taumaturgos, de 1924, Marc Bloch lembra que os ritos de cura não podem ser pensados e considerados independentemente das superstições que formam o "maravilhoso" de uma época e das "tendências gerais da consciência coletiva", uma vez que isso significava condená-los antecipadamente e percebê-los "apenas como uma anomalia ridícula" (Bloch, 1993, p. 171).

As curas realizadas pelos missionários jesuítas nas reduções da Província do Paraguai devem ser analisadas a partir dessa perspectiva, acrescentando - para o propósito deste artigo — algumas indagações: os missionários realmente curavam? Se não curavam, como mantinham a crença em seus poderes?

Valendo-nos daquilo que Michel de Certeau (1982, p. 16) chamou de "falhas" ou "lapsos na sintaxe construída" e que retornam nas "franjas do discurso", analisamos o discurso jesuítico buscando nele identificar momentos de um processo de ressignificação das representações e das práticas culturais, tanto por parte dos missionários quanto dos guarani. 
Consideramos ainda a recente produção historiográfica e antropológica para a discussão de aspectos relacionados às diferentes percepções da doença e da morte, suas interpretações e associações à feitiçaria ou à quebra de regras e/ou tabus, bem como sua profunda ligação com a religiosidade guarani.

Os indígenas sul-americanos, segundo a antropóloga Branislava Susnik (1983, p. 54), não manifestavam medo da morte, mas um profundo medo dos mortos, das almas dos mortos que colocavam em perigo as almas dos parentes vivos. Este aspecto pôde ser constatado por Viveiros de Castro (1986, p. 56) em seu estudo sobre os araweté, entre os quais "os mortos povoam o discurso cotidiano, a história e a geografia", e a morte constitui "acontecimento que põe em movimento, literalmente, a sociedade e a pessoa araweté". Entre esses indígenas,

... o período que se segue à morte de um adulto é extremamente perigoso ... o medo que se abate violentamente sobre todos, após o enterro, ... contrasta de modo visível com a ostensiva "profissão de indiferença" por ocasião do momento da morte e de exposição do cadáver. ... tão logo o cadáver sai de cena a indiferença dá lugar a um mal-contido pânico, e a inércia, à pressa (idem, ibidem, p. 491).

Para os guarani, a morte era percebida como um fenômeno puramente natural, resultante de ações más, tendo sua origem mítica explicada na conduta de Jasy (Lua), ao impedir que Kuaraby ressuscitasse sua mãe. À morte eram atribuídas causas naturais e antinaturais. A primeira ocorria "cuando el bombre o la mujer ya pasan al status de 'ancianos', carentes de 'fuerza vital', que no cazan ni desempeñan tareas propias para la subsistencia del grupo doméstico, y cuya alma encuéntrase en un estado de vagancia external"' (Bartolomé, 1977, p. 79). Por outro lado, era considerada antinatural quando associada a poderes sobrenaturais ou à magia negra praticada pelos xamãs (Susnik, op. cit., p. 54).

Para os povos primitivos em geral, estar enfermo "significa estar poseído o dominado por espiritus animales telúricos, que roban o destruyen al indivíduo, su alma, o su órgano enfermo"; e aquele que se revelar "dueño del remedio" ou "controlador de los espíritus malignos" demonstrará ter o verdadeiro poder mágico e religioso (Vara(h), 1984, p. 97).

Os missionários jesuítas registraram a crença dos guarani nos feiticeiros "enterradores", observando que:

Os piores e mais perniciosos vêm a ser os enterradores cujo ofício é matar, enterrando eles na casa de quem se deseja matar algumas sobras de sua comida, cascas de fruta e pedaços de carvão etc. Às vezes enterram sapos atravessados com alguma espinha de peixe: com o que vai enfraquecendo aquele que querem matar, e este, sem outro acidente, morre (Montoya, 1985, pp. 54-5). 


\footnotetext{
${ }^{4}$ Antônio Ruiz de Montoya nasceu em Lima, em 13 de junho de 1585 , tendo ingressado no noviciado da Companhia de Jesus em 1606. Após sua ordenação, em 1622, foi enviado à Província do Paraguai, cabendo-lhe a administração das reduções do Guairá Entre 1636 e 1637, foi superior de todas as missões da Província Jesuítica do Paraguai. O padre Montoya é considerado por especialistas no estudo das reduções jesuíticoguaranis o melhor conhecedor da cultura guarani e um dos principais autores a serem consultados para uma etno-história guarani.
}

O xamã, como detentor deste saber, é percebido pelos guarani como um ser temível, capaz de realizar feitiços e de destruir seus inimigos a léguas de distância, "y la amenaza de ser víctima de ellos está constantemente en la mente Guarani" (Vara(h), op. cit., p. 98). Nesses feiticeiros ou xamãs "encontraram [os missionários] os mais sérios obstáculos à cristianização", "seus piores inimigos ainda mais formidáveis porque neles reconheciam — da mesma forma que os índios - um poder obscuro, mas muito real: em suma, eram eles os autênticos sequazes de Satanás" (Clastres, 1975, pp. 35-6).

A morte, para os indígenas sul-americanos se reveste portanto de um complexo significado, uma vez que promove "un desequilibrio sociopsíquico en la estrecha comunidad", que é restabelecido por meio dos "ritos mortuarios y las prácticas funerarias ... conjugando o ya anulando la relación entre el mundo de los vivos y el mundo de los muertos" (Susnik, 1990, p. 103).

Entre os guarani, as práticas rituais visavam a assegurar a separação da alma do corpo morto, enquanto que a participação do rito funerário habilitava "afrontar esta fase del ciclo vital y permite su desabogo psicoemocional, incluyendo dolor, lamentación y ira". Quanto ao luto, este era percebido como "un medio para regularizar la vivencia emocional por la muerte de alguien y restabelecer el equilibrio psíquico en la comunidad', sendo que "las reacciones de los vivos frente a la muerte y a los muertos son diferentes, observando cada tribu su propia pauta" (idem, ibidem, p. 103).

O padre Antônio Ruiz de Montoya ${ }^{4}$, em Carta Ânua de 1628, registrou a forma como os guarani enterravam seus mortos, bem como as suas observações acerca daquilo que considerou "ignorançias y abusos":

... entierran sus difuntos en el campo haciendo sobre la sepultura una choquellas y de cuando en cuando van a limpiar la yerba que naçe en ella porque asi dicen que descansa el difunto, otros lo entierran en casa por tenerlos en su compañia, al tiempo de enterrar el difunto cortar los panos de las hamacas en que los entierran porque si no se moriran otros de la misma casa y por la misma raçon quitan las cuerdas de la bamaca (MCA, 1951, p. 274).

As descrições das formas de sepultamento usuais entre os guarani enfatizam que o enterro em urnas era comum, embora nem sempre praticado: "se enterraba también directamente el cadáver, pero en este caso, la fosa se calafeteaba com ramas para evitar el contacto directo del cuerpo con la tierra, y se erigía una choza funeraria en miniatura". A duração do luto era de "uno a seis meses según el grado de parentesco con el muerto; las mujeres suelen visitar la tumba para cumprir con el ritual de lamentaciones, se reincorporan a la vida normal, cuando a las mujeres vuelven a crecer los cabelos 
y a los hombres cubren la tonsura frontal basta la altura de los ojos" (Susnik, 1990, p. 113).

O mesmo padre Antonio Ruiz de Montoya, em sua obra Conquista espiritual, de 1639, registrou o seguinte costume em relação ao luto: "A la muerte del marido las mujeres se arrojan de estado medio de alto, dando gritos, y a veces suelen morir de aquestos golpes o quedar lisiadas" (Montoya, 1989, p. 78). O missionário observou também que:

Em cada parte destas regiões costuma haver usos particulares e assim, mesmo que o chorarem a seus defuntos seja coisa comum em todos e com mais intensidade quanto aos mais nobres, aqui acrescentavam o de desnudar-se uma mulher e, tomando ela um arco e setas, sair às ruas, para atirá-las na direção do sol: o que vem a ser um sinal de raiva que têm à morte, que com o desejo intentam matar. Procuram os padres evitar tais ações, por inconvenientes, mas não era possível nem lícito fazê-lo com insistência, visto tratarse de gente nova [na fé] (Montoya, 1985, p. 222).

Em relação aos rituais funerários, cabe observar que "tienen como sustrato la creencia en la reencarnación", e que "sobre todo los buesos son considerados esenciales para obtener una resurrección, o reencarnación inmediata del indivíduo"; e, ainda, que "los grandes shamanes son considerados capaces, con sus rezos, de provocar tal acontecimiento" (Vara(h), op. cit., p. 114). Estes, com suas rezas, acom-panhavam "el alma divina del sujeto hacia la morada de la deidad que lo envió" (idem, ibidem, p. 113).

As práticas de sepultamento obedeciam a concepções que envolviam "la crencia de que el alma vital del muerto acompaña el cuerpo al sepulcro, aunque separado de él, libre de su receptáculo corporal, emprendiendo recién después de un tiempo su viaje al más allá; se la separación anímica no es violenta, las almas están apegadas al mundo de los vivos" (Susnik, 1990, p. 113).

Em uma referência a essas crenças, o padre Montoya (1989, p. 78) observa que os indígenas "juzgaban que al cuerpo ya muerto acompañaba el alma a su sepulcro, aunque separada"; em razão disso, muitos "enterraban sus muertos en unas grandes tinajas, poniendo un plato en la boca, para que en aquella cavidad estuviese más acomodada el alma, aunque estas tinajas las enterraban hasta el cuello".

Os guarani acreditavam

que el "alma" del difunto quedaba "enterrada" con el cuerpo, lo que significaria un peligro potencial para los vivos; la "convivencia" del alma con el cuerpo significaria un 'poder' perturbador; según el concepto de los Guaranies, el alma, separada del cuerpo, es libre, externada, para "trasladarse" al lugar 
${ }^{5}$ Sobre a reação ao enterro cristão, Susnik (1990, p. 113) observa: "En los primeros tiempos, los Guaranies reaccionaban al entierro cristiano; agitaban el adazo sobre la tumba, trantando de liberar el alma que creian encerrada, aprisionada con el cuerpo en la tumba cristiana.... Y las urnas resguardaban los buesos, el potencial asiento del alma. En su lucha contra da cristianización, los gayráes antiguos desentarraban los buesos de los shamanes muertos, colocándolos en hamaca y cubriendo con el manto plumario; creian que sus almas volvian a tomar'su sede' en los buesos y hablar como oráculos". post-mortem y de esta manera no apeligrando ya el mundo de los vivos (Susnik, 1983, p. 67). ${ }^{5}$

Em razão disso, torna-se compreensível a resistência manifestada pelos guarani à adoção do enterro cristão, dado que “... La muerte significa la separación de la identidad anímica del hombre de su receptáculo corporal; pero, lo anímico es para los primitivos siempre uma potencia existente, transformable y también continuable" (idem, ibidem, p. 67).

Em relação à já mencionada crença na ressurreição e ao culto aos ossos, Montoya relata a prática, vinculando-a à adoração do demônio, como pode ser observado nesta passagem da Conquista espiritual (Montoya, 1985, pp. 104-5):

O demônio procura remedar em todas as partes o culto divino com ficções e embustes ... Numa das reduções estávamos sofrendo uma grande dificuldade ... até que um moço revelou a um padre ... que em três cerros havia três corpos de mortos, os quais falavam e haviam dito aos índios que não dessem ouvidos às pregações dos padres. ... Deu também o informe de que era voz corrente terem ressuscitado esses três índios ... .E, subindo com enorme custo ao cume daquele monte, descobriram um templo, em que eram honrados aqueles ossos secos. ... Recolheram os padres os ossos, junto com as suas plumas e ornatos, e levaram tudo isso .... .

É oportuno lembrar que os procedimentos adotados pelos missionários nas reduções foram normatizados pelas Instruções do padre Diogo de Torres, segundo as quais os enterros dos índios deveriam ser feitos "con solemnidad, yendo el Cura con sobrepeliz, stola y cruz, acólitos vestidos y agua bendita a casa del difunto traiendole en andas con paño negro, reçando o cantando lo que manda da Santa Yglesia" (Pastells, Pablo, 1912, pp. 352-3).

As alterações introduzidas no ritual funerário - decorrentes tanto da administração dos sacramentos do batismo, da extrema-unção ou do viático, quanto da determinação do local da sepultura e do enterro à maneira cristã — podem ser observadas nos registros do padre Montoya (1985, p. 76):

Numa peste de varíola adoeceu certo moço. ... Tive o desejo de que sua vida o Senhor ma conservasse. Na véspera de sua morte fui visitá-lo e, vendo-o muito perto do fim, disse-lhe que desejava eu sua saúde, mas que devíamos conformar-nos com a vontade divina. Disse-me ele a isso:

"Padre, acabo agora de visitar o Santíssimo Sacramento, e Nosso Senhor me deu a entender que tenho de morrer muito em breve. Estou muito consolado e desejoso de que se cumpra sua vontade".

Chamam a atenção nesse registro a manifestação de aceitação da vontade divina e a resignação diante dela, face à revelação da 
${ }^{6}$ Deve-se considerar no entanto que não se trata de uma simples transposição de representações, mas que esses relatos indicam a "construção" de representações sociais num novo contexto, o reducional, por novos agentes sociais, os índios guaranis. É acertado afirmar que os missionários manejaram símbolos e valores, definindo sua direção e assimilação. O processo no entanto esteve condicionado às motivações e aspirações dos indígenas. morte iminente. Montoya entende que a percepção da morte como libertação e condução para a vida eterna apontam para a assimilação de condutas próprias do cristianismo.

A Ânua referente aos anos de 1641 a 1643, ao registrar a prática do enterro cristão, não somente aponta para sua difusão no âmbito reducional, como realça a solenidade que o envolvia: "... la pusieron en una caja becha para este propósito, que llevaron los principales caciques y capitanes; dijosele un responso a canto de órgano, y enterráronla en el altar mayor, al lado del Evangelio con grande solemnidad' (CA 1641-3, 1996, p. 120).

$\mathrm{Na}$ mesma carta encontramos referência às missas em intenção das almas dos defuntos, o que revela outro aspecto da mencionada assimilação, pois os indígenas demonstravam: “... gran aprecio ... a los sacramentos ... y a las misas, tanto que bacen decir muchas por sus padres y madres ya difuntos, y aun aniversarios con la solemnidad que permite su pobreza" (idem, ibidem, p. 79).

Em vários relatos de batismo de moribundos encontra-se a associação entre os sacramentos do batismo e da confissão e também entre céu e inferno, revelando o universo simbólico jesuítico e o processo de produção e difusão de representações nas reduções. ${ }^{6}$ Registro singular dessa assimilação é o que relata uma mãe que, pressentindo a morte do filho recém-nascido, batiza-o, ato que denota uma 'associação mecânica' entre o sacramento do batismo, a purificação e a vida eterna desfrutadas no paraíso:

Claramente mostrou isso uma mulher cristã, que, tendo dado à luz e percebendo sinais de morte em seu bebê recém-nascido, bem como não havendo quem the chamasse o padre, levou-o ela mesma à fonte de batismo. Lá, logo depois de purificar-se, a criança voou aos céus, ficando sua mãe contentíssima por haver dado vida imortal a quem, se tardasse mais uns instantes, teria morrido à vista de Deus para sempre (Montoya, 1985, p. 194).

Igualmente significativo é o registro em que, na percepção dos missionários, aparece enunciada a relação que os indígenas estabeleceram entre pecado/morte e perdão/céu:

Oculta e torpemente vivia certa mulher, sendo disso apenas testemunha uma filhinha sua de dois anos, cuja pouca idade lhe tirava qualquer receio de sua culpa. ... Mas a menininha mostrou-se ofendida por pecado tão grande, chegou a repreender respeitosamente sua mãe lasciva e lhe disse:

"Eu quero morrer, para não ter de presenciar as tuas desonestidades. Emenda-te, pois hei de solicitar no céu o teu perdão!" (idem, ibidem, p. 205)

Nesse caso sem dúvida deve ser considerada como produto da interpretação de Montoya a consciência atribuída a uma criança de 
dois anos quanto à desonestidade cometida pela mãe. De qualquer forma, a relação entre conduta honesta e perdão remete à atribuição de responsabilidade moral, representada no relato pelas advertências que a criança teria feito à progenitora. O episódio, bem como o relato do manifesto desejo de morrer da criança, foi explorado pelo missionário, que o revestiu de tons edificantes.

A documentação analisada revela ainda que, no contexto reducional, o "bien morir" pressupunha o batismo, a confissão e a recepção dos sacramentos da extrema-unção ou viático. A passagem a seguir revela essa percepção, ao relatar que uma defunta fora amortalhada e que o tempo que deveria anteceder o enterro na Igreja havia sido respeitado.

... bapticela y despues de poco rato dio el espiritu a su Criador y antes de enterrarla, bice que estubiesse un grande rato assi amortajada como estaba, con la qual se a quitado un grande abuso, y era que apenas havia uno expirado quando luego le enterraban, ya acontecido traherme dos veces un yndio xpño. para que le enterrasen aún estando vivo, mas abora aguardan todo quanto es necesario (DHA, 1924, p. 504).

Um registro do final do século XVII permite dimensionar as alterações introduzidas pelos missionários jesuítas em relação aos rituais funerários, expressas na referência aos andores, ao cortejo, à mortalha e às louvações. Com esse relato percebe-se a normatização que cercava os rituais fúnebres, destinada a introduzir procedimentos sucedâneos de práticas rituais anteriores, como na clara referência à substituição das "lamentações fúnebres" no cortejo para a igreja, pela louvação a Deus:

As mãos do marceneiro aprontaram há dias o andor para enterros de inocentes, que uma prematura morte faz voar ao céu. ... Os carregadores destes cadáveres inocentes são igualmente seis pequenos inocentes. Para estes mandei fazer trajes novos, bordados de flores e franjas. ... Com igual brilho resplandece almofada sobre a qual reclina o feliz defunto, bem como mortalha branca que o cobre. No caminho para a igreja, em lugar das lamentações fúnebres, os músicos cantam um peã vitorioso, convidando os jovens e as donzelas a louvarem a Deus (Sepp, 1980, pp. 240-1).

Nas reduções - de acordo com os registros dos padres jesuítas —, as expressões da sensibilidade guarani diante da morte assumiram uma uniformidade e publicidade bastante distantes das espontâneas manifestações originais. Ilustrativa neste sentido é a passagem que extraímos das Ânuas referentes aos anos de 1632 a 1634, e que descrevem tanto os ritos guaranis que envolviam o enlutamento e o sepultamento, quanto as demonstrações de sentimento e devoção tidas como aceitáveis e estimuladas pelos missionários. 
${ }^{7}$ Segundo Melià (1986, p. 207), nas reduções, o enterro ocorria ao final da tarde, sendo que o cortejo fúnebre era acompanhado de "rezos y cantos de los músicos pero también

'desentonados' lamentos de indias viejas antigua costumbre que muchos años de misión no ban podido desarraigar - y en los que lloran y elogian al difunto por lo que bá sido y a becho o al menos por lo que hubiera podido bacery hubiera podido ser, de haber seguido viviendo".
Tenía muy arraigada una barbara costumbre de llorar supersticiosa e immoderadamente sus difuntos al uso jentílico de suerte que a todas horas en tiempo de peste no se oia por todo el pueblo sino funestos alaridos ... y lúgubres lamentaciones y se convidavan las vezinas a hazerlas como a coros sobre el difunto deshaziendose en llantos los dias y noches en peso. Hanla corregido por industria de los Padres mezclandola con las demonstraciones y sentimientos cristianos y piedad para con los difuntos y en oiendo el doble de la campana se juntan ordinariamente mas de 1.000 almas y le acompañan hasta darle sepultura, rezando todas con mucha devoción y compostura las oraciones de la iglesia en voz entonada (CA 1632-4, 1990, p. 37).

A descrição de um funeral que consta da Ânua do período de 1672 a 1675 - decorridos já mais de sessenta anos de atuação missionária junto aos indígenas — destaca, no entanto, a manutenção de traços do cerimonial tradicional guarani: ${ }^{7}$

Aumentó todavia más el aprecio de la religión entre los barbaros, la solemnidad com que la criatura muerta fué conducida a la sepultura en la iglesia por el camino cubierto de flores y por arcos triunfales hechos de ramas de árboles, en procesión solemne. ... Contemplaban com curiosidas los bárbaros aquellas cerimonias cristianas de la sepultura eclesiástica, porque estos indios proceden muchas veces muy de outro modo com sus propias criaturas, en su ciego gentilismo (CA [1672-1675], Leonhard, 1927, pp. 34-5).

As freqüentes referências às "demostraciones de sentimientos" pelos indígenas ganham projeção nesta passagem que trata da morte de um missionário, ocasião em que, segundo o relatante (Maeder, 1990, p. 48), se observou "un lastimoso alarido" e "un funestisimo llanto".

Los indios que con la pena de ver puesto a su Padre en aquel trance no sosegavan, se avian juntado muchos y tenian en aquella sazón cercada nuestra casa, dioles aviso de la muerte el doble de las campanas, y alçaron todos un lastimoso alarido, siguiendole luego todos los demás que estavan esparcidos por las rancherias del pueblo en los quales se oían tales extremos de sentimiento y de funestisimo llanto, que representavan quanto a esto uno de aquellos dias confusos $y$ temerosos que han de anteceder al del juicio. No fueron solos los indios los que hicieron estas demostraciones de sentimientos aunque ellos tenian más razón de lastimarse por aver sido para ellos maior la pérdida y hasta agora no acavan.

Este registro permite inferir que o "chorar copioso", manifestação nitidamente vinculada a uma encenação ritual tradicional, assumiu aos olhos dos missionários a condição de consciência de culpabilidade e demonstração pública de arrependimento, como fica atestado nestes trechos da Ânua de 1632-1634 (idem, ibidem, p. 71): 
Mas el Padre penetrando blandamente sua corazones sus amorosas palabras, les hizo volver en sí, y que se dispusiesen en aquel riguroso trance con mucha penitencia y lágrimas, acavaron todos confesando sus delictos, y deseando muy seguras prendas de la misericordia, qu el señor avia usado con sus almas.

Pregando por "inspiración sensible", os missionários instavam os indígenas a sentirem "el remordimiento de su conciencia", o que tinha, segundo eles, efeitos surpreendentes sobre as condutas dos indígenas. Isso pode ser observado na seguinte passagem da Ânua de 1659-1662:

Un día (un hombre) vio como predicaba uno de los padres misioneros contra el crimen dela hipocresia y de ocultar pecados en la confesión. ... Causóle a aquel infeliz tanto dolor que le costó contenerse para no con alaridos manifestarse como el hombre más perdido del mundo. Luego despues del sermón se puso a llenar tres hojas de papel con las listas de sus pecados, entre torrentes de lágrimas. Echóse a los pies del confesor y le entregó el papel entre muchos sollozos y bañado de lágrimas, desmayándose casi de dolor $y$ arrependimiento (CA [1659-1662], Leonhardt, 1927, p. 77).

Expressões como "bañado en lágrimas", "con lágrimas de dolor y arrepentimiento" e "torrentes de lágrimas" são usadas de forma recorrente na documentação jesuítica para ressaltar a assimilação pelos indígenas das expressões de piedade e devoção tridentinas. Cremos, no entanto, que a assimilação a que se referem os missionários aponta mais uma vez para a ressignificação das manifestações tradicionais de sentimentos de emoção individual e coletiva dos guarani.

Em outras situações, o costume da "saudação lacrimosa" entre os índios é apresentado como manifestação de caridade e comoção própria dos cristãos:

Esta reducción de Loreto no solo es la más antigua de todas en el servicio de Dios, sino también la más constante en el ejercicio de la caridad. ... Resplandeció sobre manera su caridad en ocasión de la transmigración de tantas reduciones. ... En el momento de encontrarse, quedaron tan conmovidas ambas partidas, que largo rato no podían hablar, sino sólo llorar, hasta que al fin se saludaron mutuamente según su costumbre propia, abrazándose con efusión, y sacando en seguida los refrescos y las provisiones. Era un espectáculo ternísimo (apud Maeder, 1984, p. 93).

Mencionam-se lágrimas, soluços, gritos e suspiros para ressaltar o nível de comoção e comunhão coletiva dos indígenas, alcançado nas missas, procissões e festas religiosas. Orientadas e estimuladas pelos missionários, essas manifestações estavam bastante distantes — no plano do discurso - daquelas condutas descritas como exteriorização brusca e ruidosa de sentimentos e qualificadas como condenáveis "ignorancias y abusos". 
${ }^{8}$ Para Métraux (1944, p. 157), "Es indudable que gran número de enfermedades e incluso de accidentes debidos a torpeza" era percebido pelos indígenas como "manifestaciones de la mala intención del bechicero o de los espiritus; pero no debe deducirse de ello que colocan en el mismo plano todas las afecciones que sufren". Isso porque os índios cuidavam "por si mismos las afecciones que consideran como ligeras o se ponen en manos de un curandero - hombre o mujer que los trata con medios sencillos o con fórmulas mágicas; pero aún se la curación tiene carácter puramente mágico, la actitud del paciente demuestra que no se considera victima de una fuerza sobrenatural peligrosa".
Conforme já se observou, para os guarani as enfermidades têm um caráter mágico, uma vez que são atribuídas à intrusão de um corpo estranho no organismo, ou a um malefício enviado por um inimigo. ${ }^{8}$ A relação entre infrações do código moral e enfermidade se manifesta entre os indígenas sul-americanos do modo como foi observado por Susnik (1989, p. 157):

El hombre es consciente que todo o existente establecido puede reaccionar a él, cuando ocurren transgreciones del equilibrio de la vivencia; pueden irritarse las deidades, los dueños de animales y naturaleza o ya las almas des-idas de los muertos, infligiendo los "castigos" de acuerdo a las violaciones sociomorales .

Cabia ao xamã a reversão desses feitiços; caso se tratasse de feitiçaria, "los gusanos 'extraídos' se colocan en un tubo de 'takwara' entre viruta tapándolo", enterrado "cerca del fuego; el mismo calor del fuego mata a la 'enfermedad' y fulmina al respectivo hechicero" (idem, ibidem, p. 157).

Alfredo Vara(h) (op. cit., pp. 103-4) relata as técnicas curativas xamânicas que incluíam "viajes' imaginarios o alucinatorios, dramatizados por el shamán, repetiendo etapas previamente ejecutadas" que tinham "la finalidad de rescatar el alma del paciente o de interceder por ella ante los dioses o genios celestiales".

Lévi-Strauss (1968, pp. 162-3), no entanto, observa que não se deve entender "la cura shamánica como una maniobra con un único protagonista", pois "el complejo shamánico se compone de tres protagonistas: enfermo, shamán y comunidad". A eficácia dos rituais reside no consenso de que o xamã cura porque é considerado por todos um grande xamã; logo, seu poder somente se mantém enquanto "cuenta con la fe y la participación de la comunidad" (idem, ibidem, p. 162).

Em seu estudo sobre a medicina pré-hispânica, Carmen Téllez (1993, p. 110) remete à uniformidade do tratamento das doenças por parte dos xamãs sul-americanos, já apontada por Métraux.

Ante el enfermo procedia a hablar con él y con sus familiares para averiguar la causa del mal, después le palpaba todo el cuerpo y procedia a chupar la parte lesa para con este ritual extraer el daño. Mediante drogas alucinatorias, se ponía en contacto con los espiritus y prognosticaba el curso de la enfermidad.

Ao descrever a terapêutica guarani, a autora afirma que "estaba basada en el uso de las plantas, algunas con virtudes medicinales, pero todas ellas con propiedades mágicas curativas. Se administraban por via oral mediante infusiones, o como astringentes y emplastros en picaduras y otros usos tópicos" (idem, ibidem, p. 110). 
Quanto às práticas de caráter preventivo e terapêutico difundidas entre os guarani, eram freqüentes as escarificações, as cauterizações, a aplicação de ventosas e os emplastros, conforme descrição abaixo:

... las escarificaciones hechas en los brazos o en las piernas con objetos punzantes para descongestionar y evitar el cansacio. Ante una picadura ponzoñosa, acercaban la parte lesa al fuego sin llegar a tocarlo, hasta que se adormecía el dolor. También usaban en estas picaduras ventosas hechas con la corteza de calabaza y era tan frecuente su uso que nunca emprendian viaje sin llevar estas ventosas. Los rasguños y pequeños cortes eram tratados con plantas astringentes $y$ de alto contenido en aceites esenciales; en cambio las grandes heridas eran vendadas con tejidos de algodón $y$ a veces tratadas con hojas de tabaco, especialmente si eran beridas gangrenosas (idem, ibidem, p. 110).

O jesuíta Montoya, além de registrar o amplo e difundido uso de ervas medicinais, ressaltou o caráter supersticioso da atuação do xamã:

Usam os índios muitos remédios e ervas (medicinais), que lá a natureza tem produzido. A pedra de São Paulo é de ajuda comprovada; são-no também os alhos esmagados, ingerido o remédio como bebida, a pedra bezoar e outras ervas [medicinais]. Mas mais caseiro é o fogo, queimando-se com uma faca em brasa a parte ferida pulverizada com enxofre. É conhecido este remédio e, acudindo-se a tempo, gente picada por tais cobras está fora de perigo. Os fígados da víbora, sendo ingeridos com alimento, usamnos como remédio (Montoya, 1985, p. 25)

E adiante:

As superstições dos feiticeiros baseiam-se em adivinhações por meio dos cantos das aves: do que inventaram não poucas fábulas relativas a medicar e isto com embustes, chupando, por exemplo, ao enfermo, as partes lesadas e tirando o feiticeiro da boca objetos que nela leva ocultos ou escondidos, e mostrando que ele, com sua virtude, lhe tinha tirado aquilo que lhe causava a doença, assim como uma espinha de peixe, um carvão ou coisa semelhante (idem, ibidem, p. 54).

As referências feitas aos xamãs na documentação jesuítica setecentista se caracterizam pela descrição como sacerdotes do Diabo, ministros do Demônio, "que hacen cosas que espantan y no pueden ser sino por arte del demonio" (Arrospide, 1997, p. 99); "oradores natos, usan de todo el aparato solemne de gesticulaciones; los misioneros serán con frecuencia impactados por su expresividady por su noble lenguaje. Otras veces apenas podrán contener la risa ante tanta gravedad fingida" (idem, ibidem, p. 101).

Com relação às atribuições de curandeiro ao xamã, são freqüentes descrições como a de que "... hablan con el demonio por medio de 
${ }^{9}$ De acordo com Furlong (apud Echenique et. al., 1985, p. 252) os guarani tinham seus médicos e "medicinas, estribando casi todas estas en el uso de cortezas, semillas, jugos de plantas y árboles de la región". Nora Echenique e Miriam Ferreira relatam a utilização de ungüentos contra mosquitos e como protetor solar, além das escarificações feitas com "espinhas de pescados, aguijones de palmera o dientes de acutí, combatendo asi la pesadez del cuerpo y el cansancio mismo", da "curación ignea" na cauterização de feridas; das ventosas e dos antihelmínticos que viriam a ser empregados por toda a população colonial americana (idem, p. 252).

${ }^{10}$ Garlet (1997, pp. 40 1) observa que "os próprios missionários eram, em muitos casos, os agentes transmissores de doenças. Em algumas circunstâncias o efeito das epidemias frustrava as suas expectativas, enquanto que em outras assinava o aval de seu ingresso nas aldeias, sendo tomados por grandes pajés que sabiam como tratar estas novas e estranhas doenças". Por outro lado, "as epidemias em muitos casos evacuavam as populações nativas de extensas áreas, liberando-as aos colonizadores. Acompanhando o histórico dos contatos entre os antigos Mbyá com a sociedade colonial, fica evidente que os colonos foram se estabelecendo sobre seu território à medida que as doenças produziam verdadeiras clareiras demográficas". la yerba, ... cogen las brasas encendidas en las manos sin quemarse $y$ se las comen a bocados, como si fuera cosa muy gostosa y comestible", ou, ainda, que "bacía abrir un agujero en el techo, por donde habia de entrar el mal espiritu, le daban unos desmayos y hacía fieros visajes y meneos" (idem, ibidem, pp. 99-100).

A eficiência do xamã e a eficácia de sua terapêutica são referidas por Guillermo Furlong (1962, p. 604) ao afirmar que, "con anterioridad a la labor misionera entre los Guaranies, y antes de la venida de los españoles, estos indios eran sanísimos, y como se expresaba un misionero al referirse a ellos, sólo conocían una enfermedad: la vejez".?

Apesar da disponibilidade de uma farmacopéia rica, as pestes que os missionários jesuítas registraram em suas Cartas Ânuas não puderam ser evitadas e nem eficazmente combatidas, dado que os indígenas estavam desprovidos de anticorpos para delas se defenderem.

Há unanimidade entre os historiadores quanto à estreita vinculação de implantação das reduções e pestes.

La concentración de varios millares de indios en una sola aldea revoluciona de tal manera la economía tradicional. ... Al debilitar a los indios, esta hambre favorece la propagación de enfermedades importadas, contra las cuales su organismo no tiene defensa. Más o menos violentas, más o menos fulminantes, siempre, al decir de los propios jesuitas, las epidemias causan estragos entre las nacientes cristiandades; $y$ la concentración de los catecúmenos no hace sino favorecer la becatombe (Haubert, 1987, p. 254).

Doenças desconhecidas como gripe, sarampo, varíola, tuberculose, febre amarela, malária, pneumonia epidêmica, disenteria, cólera, tifo, sífilis, lepra e doenças venéreas debilitaram e desorganizaram as populações atingidas, facilitando o avanço da frente espanhola e provocando, "además de su bundimiento demográfico, la más total desmoralización del índio" (Meliá, 1986, p. 87). ${ }^{10}$

Considerando o imenso território que os guarani ocupavam no século XVII, as epidemias eram facilmente propagáveis, pelo tamanho da população e a intensa comunicação existente entre as aldeias, ligadas por uma rede de trilhas e caminhos abertos no interior das florestas ou pelos cursos d'água.

Esse aspecto pode ser observado na Carta Ânua de 1634, na qual o padre Romero atribui a propagação das epidemias ao fato de os guarani serem "naturalmente andarilhos", sendo que poucos "escapavam de padecer destas pestes e enfermidades e, assim, uns sucessivamente a outros vão caindo" (apud Vianna, 1970, p. 129).

O mesmo padre Romero, além de nos oferecer sua interpretação com relação às possíveis causas e natureza das epidemias, deixa entrever a concepção galênica de doença, ao observar: 
... têm quase todos as mesmas complexões, as mesmas comidas, e guardar todos ou uma, sem discrepar um mesmo teor de vida, e assim as enfermidades nascidas destes humores e destemperanças de comidas etc. são as mesmas em todos (apud, idem, ibidem, pp. 128-9).

Na mesma carta faz-se referência à forma como os missionários contornavam a falta de pessoal para o atendimento dos doentes, e que pode ter causado a disseminação das epidemias: "... muitas vezes enviamos às aldeias antigas dos índios um mancebo enfermo." (apud, idem, ibidem, p. 112).

Isso sem dúvida facilitou a disseminação das epidemias entre os guarani, uma vez que não se evitaram os contatos - fruto da ignorância científica da época — que teriam impedido a contaminação. Não só os padres como os índios contaminados iam continuamente às aldeias que muitas vezes ainda poderiam estar livres de doenças.

Os males trazidos pelos espanhóis colocaram, portanto, os guarani frente a uma necessária reformulação, não somente em termos de percepções, mas também de práticas, o que pode ser observado tanto no Tesoro de la lengua guarani quanto no Vocabulário de la lengua guarani, organizados pelo padre Antônio Ruiz de Montoya, que registram, entre outras, as expressões ligadas a doenças, epidemias e reações dos índios frente às suas desastrosas conseqüências.

As epidemias, definidas como "peste" ou "enfermedad" pelos jesuítas foram denominadas pelos guarani como mbaba, taçi ai, maraa, mbae açi. Entre as doenças epidêmicas destacam-se: tepotí ugui ou tepoti pyta ("camaras de sangre/disenteria"); mbirua ("ampollas/sarampo"); acanundu yrundi ara — naboguara ("quartãns/malária").

Como expressões reveladoras da percepção e dos efeitos das epidemias destacamos: nache mo amongueri taci ("a enfermidade levou minha gente"); chembotiabo mbar raci ("a enfermidade acabou com a minha gente"); y pichibi tabaa oupa hacipabamo ("está a aldeia espantada com tantos enfermos"); mbae aci oqui rucu ore rebe ("chove a enfermidade sobre nós").

Cabe observar que, em alguns registros, os padres admitem que as doenças não decorrem exclusivamente da "divina justicia", mas da "consecuencia de la transmigración y el cambio de clima aparecieron frecuentes dolencias en el pueblo", oportunidade para 'experimentalismos', como na referência a que "aplicaron las medicinas del campo de aquella región, pero sin ningún resultado"; e ainda para recrutar enfermeiros entre os índios sãos, "para investigar si los habia [enfermos] en las casas, campos y selvas" e vigiar "contra la antigua superstición de los hechiceros" (Maeder, 1984, p. 88). 
As passagens abaixo ilustram o senso de observação prática dos missionários e a relação que estabeleceram entre as doenças e as condições de assentamento das populações indígenas.

... tierra pantanosa y llena de lagunas y mosquitos, habiendo padecido por ello muchas enfermedades (Pastells, Pablo, op. cit., p. 180).

Desta peste dicen que es causa el rio porque ha crecido supra modum y fuera del curso natural con dos crecientes, que después que iba baxando ya, a su tiempo, torno a crecer outro tanto $y$ mas, y aora esta in summo sin aber abaxado, y asi ban las enfermedades con el río. Hanse visto en el pescados disformes de grandes, sobreaguados muertos, que dicen traían la pestilencia con muchas vivoras que cogia la corriente (idem, ibidem, p. 181).

Interessante observar que esses missionários referem-se com freqüência à "plaga del hambre", face à constatação de que "la escasez de sólido alimento produjo toda clase de enfermedades", não descuidando de registrar de forma bastante detalhada o processo das doenças (o contágio, as tentativas de cura, empíricas ou exorcistas, ou então a morte), bem como as principais enfermidades (gripe, disenteria, lepra, sarampo, tifo, varíola) que se abatiam sobre indígenas reduzidos e colonos espanhóis instalados nos pueblos.

As passagens que transcrevemos são ilustrativas, e não só da preocupação com o detalhamento da evolução das doenças. Também revelam a percepção ocidental de doença pelas imagens que constroem um "retrato de la muerte", bem como pela possível vinculação ao demônio.

Los aires del mar causaron una epidemia tan atroz que podia uno durar si tenía causas naturales o si era producida por el mismo demonio. Comenzaba la enfermedad con un intolerable dolor de cabeza. Luego torcianse los ojos y perturbábase la razón. Extendiase el mal hacia el cuello, y quitaba la facultad de tragar y hablar. Despues salieron úlceras tan feas en la garganta, que inficionaban con su mal olor en tal grado el aliento, que el mismo enfermo parecía abogarse entre insoportables sufrimientos. En seguida se cubría todo el cuerpo con una erupción semejante a la lepra, y en las entrañas se formaban unos gusanos peludos de asqueroso aspecto, que causaban a los enfermos agudisimos dolores. Al fin se hinchaba borriblemente la cara y reventaba en llagas como paperas (DHA, op. cit., 1929, p. 681).

Esta peste postró en menos de ocho dias a toda la población a grandes y chicos, hombres y mujeres. Sólo yo y un jóven quedamos en pie. ... Adonde me volvía, no veía yo sino oscuras llagas, apostemas destilando pus y gusanos, y en todas partes se me presentaba el retrato de la muerte. Y para cuidar a cuatro mil 
enfermos quedaba sólo yo con aquel joven. Aconsejáronme algunas personas, sería bueno, snagrar a los dolientes (idem, ibidem, p. 681).

Estas são descrições que sem dúvida exploram amplamente as sensações de dor, compaixão e repugnância, pelo forte apelo aos sentidos do olfato e da visão. Se as doenças são descritas com colorações tão realistas por homens experimentados e familiarizados com as epidemias na Europa, pode-se avaliar o impacto que a evolução das doenças introduzidas pelos europeus causaram nos indígenas, traumatizando-os e predispondo-os a buscar a salvação da alma na conversão ao cristianismo.

O discurso jesuítico reflete o próprio espírito da época, marcado pelo embate entre racionalismo e misticismo, o que fica evidenciado nos registros que selecionamos a seguir. A primeira passagem foi transcrita da Carta Ânua de 1637-39, de autoria do padre Francisco Lupercio de Zurbano (Maeder, 1984, p. 125), que expõe primeiramente a versão da interferência da "divina justicia":

Cuando el hambre estaba en su apogeo en este pueblo, fueron enviados algunos indios de aqui al pueblo de Concepción, para pedir lismosna a los Padres, un poco de provisiones como alivio en tanta necesidad. ... el Padre se olvidó añadir a ella algo de carne para ellos. ... Tres de los indios quisieron tomar venganza del olvido del Padre; agarraron el buey [que estaba pastando], lo mataron y repartieron los cuartos. Ponen algunos de estos últimos en un asador de palo, después de haber comido ya otros cocidos. ... Pero sucedió que les alcanzó el castigo de Dios. Así como estaban sentados alrededor del fuego, dando vuelta al asador, cayeron de espaldas con sus miembros al aire, y mientras con débil voz rezaban el Padre Nuestro y Ave María, se murieron. Los demás quedaron con el susto dos días sin querer comer, y escarmentados en cabeza ajena aprendieron, juntamente con todo el pueblo, a temer a Dios.

Em seguida Zurbano (idem, ibidem, p. 125) nos apresenta uma percepção mais racional, sem descuidar no entanto de ressaltar os desdobramentos do que ocorreu, em termos de conduta dos indígenas.

Algunos de nuestros Padres refirieron este caso de un modo algo diferente. Podia ser que, debilitados por el hambre, comieron de una vez demasiada cantidad de carne, dañandose asi su salud y ocasionándose la muerte repentina. Así no hubiera venganza de Dios por el robo cometido, sino efecto natural. A lo menos enseña este ejemplo que la muerte es buena maestra.

No distante ano de 1663, situação similar voltaria a ser relatada pelo provincial Andrés de Rada (apud Leonardt, 1927, p. 103), que, a exemplo do seu antecessor, sugere que, em termos de explicação, prevaleça aquela que promove "reforma de costumbres": 
Por el año de 1663 cierto sudor extraño agitó los sentimientos religiosos, tenido por algunos por milagro, por otros por funesto presagio, otros juzgaron de otra manera; pues esta humedad destilada en gran cantidad de las imágenes, tenida por milagrosa por algunos, la tienen otros por muy natural a cuadros al oleo, atribuyéndole a una descomposición de los ingredientes de la pintura. Yo, por mi parte, no excluiría del todo una intervención de la Providencia, ya que suele producir tal caso un efecto moral, y una saludable reforma de costumbres. Consultado un Padre sobre este caso, explicó que lo mejor sería arrepentirse de sus pecados y practicar austeridades corporales, para alejar de nuestras cabezas el flagelo de la divina justicia.

A associação entre conversão, cura e oferta de alimentos, admitida pelos próprios missionários, é apresentada como determinante para a permanência nas reduções e para o abandono das antigas práticas.

Valió mucho para que no pereciesen todos la industria del Padre Pedro de Mola, provo a sangrarles y sanaron algunos y así se llenava todos los días nuestra casa de apestados que acudian ansiosos y deshados para que el Padre les diese de comer y les sangrase por sus manos pidiendo todo el pueblo a vozes a Nuestro Señor misericordia y muchos por aquel medio la alcançaron y derramandose por la tierra adentro la fama acudian los jentiles a tropas para que el Padre exercitase con ellos la misma piedad ... los quales no sabiendo como agradecerlos todo el dia se andavam tras de el Padre haziendole mil caricias y allagos y la puerta de casa muchos regozijos y fiestas las noches a su usanza para tenerle contento y los ya cristianos dexandose formar de su doctrina en toda piedad cristiana y cortar lo vicioso y uvo muy señaladas conversiones y los jentiles disponiendose con gran fervor para el baptismo (Maeder, 1990, p. 167).

Os missionários se dedicam igualmente a enfatizar os prejuízos que a fome e as epidemias causavam ao projeto reducional, como fica expresso nesta passagem:

Perecia de ambre el pueblo. ... Los mas dellos con esta ocasion desampararon el pueblo, $i$ recurieron por comida a los sembrados de sus tierras antiguas, donde no avia llegado esta plaga, $i$ se vieron los padres en mucho trabajo para hacerlos volver a la redución porque alegaban se cansaban en sembrarpues los ratones lo destruian todo (DHA, 1929, p. 287).

O comprometimento da conversão dos indígenas fica igualmente visível na interpretação dada à praga de ratos e que expõe a reincidência nas 'superstições'. "Y casualmente, al tiempo de sembrar, aparecieron enjambres de ratones, nacidos por la sequí, y comenzaron a devastar los campos, por lo cual que algunos victimas de su superstición lo atribuyeron a brujería" (idem, ibidem, p. 591). 
Se, por um lado, o retorno aos "sembrados de sus tierras antiguas" prejudicava o trabalho dos missionários, por outro favorecia os magos que lhes atribuíam a responsabilidade pela fome e pelas epidemias - e prometiam restaurar a felicidade perdida.

Mucho trabajo les causó cierto célebre hechicero llamado Yaguacaporo, el cual propaló que era una divinidad, y que se le debia venerar como a dios, asseverando que él había hecho el cielo $y$ la tierra, y que el podia producir buon tiempo y mal tiempo, y que era dueño de vida y muerte (idem, ibidem, p. 556).

A documentação que analisamos enfatiza a condenação das práticas terapêuticas xamanísticas, destacando sua inadequação, em decorrência do caráter demoníaco e mágico-supersticioso implícito nos rituais de cura. Os registros revelam, contudo, que práticas como presságios, relíquias, rezas e ervas, sopros e sucções, condenáveis quando executadas pelos xamãs, foram aplicadas pelos missionários com uma justificativa igualmente mágico-religiosa. Estes, assim como os xamãs, valeram-se da imaginação e do misticismo dos indígenas.

Condenada como prática terapêutica xamanística, a sucção de ferimentos ou de partes do corpo do enfermo constitui exemplo paradigmático do processo de ressignificação em curso nas reduções jesuítico-guaranis. Na passagem que transcrevemos a seguir, o missionário ressalta seu caráter taumatúrgico, não esboçando qualquer recriminação a essa prática:

Un indio sufría una enfermedad muy asquerosa, resistiendo sus apostemas a toda curación. Nuestro Padre, empero, quiso vencer la repugnancia y sanar al enfermo y por eso pensaba que lo mejor sería besar las llagas como si fuesen rosas flagrantes y chuparle la materia infecta (CA [1663-1666], 1927, p. 92)

Amuletos, relíquias e água benta não possuíam virtude sobrenatural intrínseca, mas produziam preciosos efeitos, diminuindo a ansiedade dos doentes e predispondo-os à cura pela imaginação e pela fé. Registros de curas milagrosas, como aqueles que destacamos adiante, são bastante freqüentes na documentação jesuítica e ressaltam não somente o uso de práticas mágicas, mas também seus desdobramentos nas reduções.

Una india de pies a cabeza cubierta de lepra despues de baptizarla con la salud del alma se sirvió Nro. Señor comunicarle también la del cuerpo - tienen estos indios particular devoción al agua bendita por las mercedes que Nro. Señor por su medio les hace, algunos que an padecido mal de ojos con solo lavarse con esta agua quedaban sanos (CA [1616], 1929, p. 28). 
$\mathrm{Na}$ carta do padre Marcial de Lorenzana ao provincial, padre Diego de Torres, de 19 de julho de 1610, esses aspectos podem ser observados, permitindo, inclusive, uma aproximação com os 'reis taumaturgos' de Marc Bloch:

Esta reducción, a toto genere va cada dia mejor, y los indios y indias se pasan de muy buena gana al asiento nuebo. Despues de mi buelta se han animado mucho, y dicen q. han conocido ya el grande amor que les tengo, va acudiendo mas gente, muestran deseo de baptismo, no se nos muere nadie en las enfermedades, los que se han baptiçado in articulo mortis han sanado, tienen gran devoción con los evangelios y dicen que quando el $P^{e}$. les pone las manos en la cabeça les pone una cura con que ellos sienten q. los sanan; los q. tenian dos mugeres las van dejando y hacen otras cosas en que dan muestras de temer a Dios (apud Pastells, Pablo, op. cit., p. 163).

Os abundantes relatos de curas milagrosas não só atestam a presença da visão seiscentista da doença e da morte; testemunham também práticas dela decorrentes ao registrarem o uso da "tierra de San Pablo", do "licor de S. Nicolas", do "milagroso sudor" e dos sacramentos do batismo e do viático:

... dos indios viejos que avian sido mordidos de unas vivoras tomando tierra-de-San Pablo quedaron sanos, con que se van afficionando a las cosas de nra santa fé (DHA, 1929, p. 98).

A una niña q. estava muy al cabo baptizo el Pe en los braços de su $m^{e}$ y luego la biço dar un poquito de licor de S. Nicolas começo a mejorar luego y sano en breve. ... otro yndio enfermo de camaras de sangre estava tan al cano q apenas se podia cathequizar recebio el sto. baptismo començo luego a mejorar sano perfectamte y el mis decia q Dios le havia sanado por medio del $s^{\text {to }}$ baptismo (idem, ibidem, p. 100).

Aplicó-se el milagroso sudor, y sintió ella alivio, cerrándose el otro día la llaga, de la cual sólo le quedó la cicatriz. La misma escapó por este mismo remedio del inminente peligro de muerte a consecuencia de la peste, pudiendo ya el dia siguinte, sana y buena, irse para dar las gracias a su protectora. En una, palabra, este remedio sirvió para toda clase de enfermedades, no sólo del cuerpo como del alma (idem, ibidem, p. 520).

Ni solo obra nro. Sr estos milagros en las almas destos nuevos Xpiânos, sino tambien en los cuerpos. Fue un padre a visitar un enfermo $i$ ballale con el pecho ia inchado i para rendir el alma; supo no avia recivido el viatico. Tomolo el doliente ... con mucha fe $i$ devocion; mostrolo el efecto porque luego se sintio mejor y el dia siguinte sanó del todo (idem, ibidem, p. 314). 
As expressões "con que se van aficcionando a las cosas de nra. santa fê", "q. Dios le havia sanado por medio del sto. baptismo" e "con mucha fe i devoción", mais do que revelarem a estreita relação entre cura e conversão, refletem a aceitação de novas práticas curativas pelos indígenas, sem no entanto promover a descaracterização do componente mágico tradicional da terapêutica indígena.

A difusão das práticas de caráter mágico é justificada pelos missionários pela ausência de remédios, pela "debil medicina", ou pela sua condição de "medicos no solo de sus cuerpos, pero tambiém de sus almas":

... tambien con los pocos remedios que aca ay procuramos curarlos por que ellos no tienen medicinas ni hacen remedios sino dexassen morir. El año pasado dio una enfermedad de catarro de que enfermo caso todo el pueblo y el padre Juan de Salas les biço un jarave con que sanaron casi todos aunque algunos murieron, ... aunque algunos les vino tanta abundancia de flemas que no las pudo vencer tan debil medicina y otras que a avido (idem, ibidem, p. 88).

... pero poco a poco se van desengañando, y viendo con sus ojos los yndios como los nros les son verdaderos padres dando-les con amor de tales quanto piden como lo aya en casa, y siendoles medicos no solo de sus almas q es lo principal, sino de sus cuerpos ayudandoles en todas sus enfermedades y trabajos de noche $y$ de dia (idem, ibidem, p. 24).

Os jesuítas acreditavam numa "certa predestinação" para sua atuação como "médicos do corpo e da alma", o que lhes conferia uma presumida imunidade face ao inevitável contágio em tempos de peste.

Mientras tanto se declaró una epidemia que hizo gran estrago. ... El contágio se hizo tan general en la ciudad que prostró también a todos los sacerdotes, menos a los de la Compañia, para que pudiesen asistir a los moribundos. No bicieron solamente esto, sino repartieron medicinas para los enfermos, y limosnas a los pobres (idem, ibidem, p. 523).

A resistência ao uso da terapêutica indígena disponível não se restringia ao tratamento dos índios, podendo ser também observada no tratamento das enfermidades dos próprios missionários, como fica claro na "Informação sobre a Redução de Nossa Senhora de la Natividad del Acarayg" (idem, ibidem, p. 294):

Yo avia mas de mes $i$ medio que lo estaba de tiriçia ... e el $P^{e}$ Claudio con su gran caridad hiço una chozuela con unos cueros, ... $i$ alli cobre alguna mejoria, mas con las oraziones/las oraziones del $P^{e}$ que con outro remedio, que no le avia, ni regalo ninguno. 
O registro atesta ainda a crença na intercessão divina e na eficácia das orações, coerente com a percepção de cura dos missionários que não só consideravam natural invocar a ajuda de Deus, como também recebiam com naturalidade a misericórdia divina.

Com igual naturalidade atribuíam as pestes à manifestação da cólera divina, o que fica atestado na vinculação dela com o castigo:

... con estas cosas pareze q. suficientemte nos habia ayudado el Señor dandonos a entender, que queria el mirar por este pueblo, pero aun mas claramente nos lo ha manifestado castigando a otros. ... Al oir los indios de los Padres, que semejantes epidemias son instrumentos de la divina justicia, se fueron a ellos rogándoles que organizasen solemnes rogativas para aplacar la ira de Dios (CA [1635-1637], 1929, p. 702).

Se, por um lado, as epidemias eram consideradas "instrumentos de la divina justicia", seu controle ou a redução de seus efeitos danosos passaram a ser considerados indicativos da proteção divina, garantida pela conduta exemplar dos indígenas.

São numerosos os relatos em que os missionários registram os efeitos que essas intervenções divinas - por intermédio das pestes ou das curas milagrosas - produziam sobre a conduta moral dos indígenas, bem como sobre os múltiplos recursos empregados (procissões, remédios, sangrias, relíquias e confissões).

Los otros dias dando una enfermedad, de S. Ignacio se hizo una procesion muy solemne llevando de un pueblo a otro la ymagen con que el sor servido no pasase adelante la peste y en outra dize los indios gras al sor estan muy adelante en las cosas de Dios, no ay borracheras ni amancebam ${ }^{\text {tos }}$ donde muchos estavan enredados antes en avominables vicios los quales avominan abora (DHA, 1929, p. 146).

Cogiose deste trabajo grande fructo con confesiones generales, $y$ mudanças de vida porque se le offrrecieron a los $P^{e s}$ lances muy venturosos, e bizieron hablar a muchos demonios mudos, que se avian apoderado de los corazones largos años, y talvez teniendo perdido el habla y aun el sentido se la restituyo nro $S^{r}$ milagrosamte para que se confessasse tocandole con una milagrosa ymagen de nro $P^{e}$ S. Ign. (idem, ibidem, p. 427).

Há que considerar - como já foi mencionado - que as Cartas Ânuas consultadas enfatizam os relatos edificantes, relatando essencialmente os casos de doentes que se disseram (e se mostraram) curados após a intercessão dos santos, da água benta, do batismo ou das relíquias sagradas.

Não encontramos, nos registros relativos ao período em questão, qualquer referência aos insucessos nas tentativas de curas, ou, ainda, menção a recidivas das doenças atestando que a terapêutica empre- 


\footnotetext{
${ }^{11}$ É oportuno lembrar que o medo e a desconfiança iniciais foram cedendo diante do 'poder de cura' demonstrado pelos missionários frente às doenças desconhecidas e à ineficácia das práticas tradicionais de cura dos karaí nativos. Conforme Garlet (1997, p. 41) "não era a cura da alma ou do espírito que o demovia a aceitar o missionário, mas a cura dos males físicos".
}

gada não havia sido eficaz e levou o indígena a repeti-la ou então a desacreditá-la.

É preciso ressaltar ainda que a medicina de outrora era praticamente incapaz de descobrir e avaliar as recidivas das doenças. Além disso, os médicos, no séc. XVII, não tinham à disposição uma terminologia muito rigorosa nem métodos de diagnóstico muito seguros. Havia, em razão disso, algumas doenças capazes de produzir facilmente a ilusão de cura.

Quando as enfermidades cediam ou pareciam ceder, dando a 'ilusão da cura', estabelecia-se uma relação entre fé e milagre, pecado e perdão, conversão e cura - fundamental para o projeto de conversão e civilização dos missionários jesuítas.

Da mesma forma que os registros permitem verificar a manipulação das curas, eles revelam igualmente a manipulação das nãocuras, como no caso das mortes resultantes de epidemias ou doenças graves, instrumentalizadas para difundir novas condutas morais e a crença na salvação da alma.

Deve-se contudo reconhecer que "un solo médico no podía dar atención eficiente a cien mil indios, ni siquiera a la mitad", o que pode ter significado "que las recetas y soluciones indigenas debian ser de uso general' (Echenique et al., op. cit., p. 260) ${ }^{11}$, permitindo a sobrevivência das práticas curativas xamanísticas, bem como a receptividade às prédicas dos magos.

A contestação e perseguição que os missionários empreenderam aos magos ("bombres-dioses") que "profieren amenazas apocalipticas" (Haubert, op. cit., 1987, pp. 253-4) devem ser compreendidas, em razão disso, não como um combate às ervas, poções e bálsamos empregados pelos xamãs nas curas, mas como um repúdio à mística envolvida nessas curas e aos rituais mágicos que garantiam sua eficácia. Daí ser possível perceber o confronto entre xamãs e missionários como uma disputa de saberes e poderes pelo controle das doenças e pela manipulação das curas e nãocuras.

À proporção que não foram propriamente os recursos medicinais a sofrer contestação, mas sim sua eficácia ritual, os registros feitos pelos padres jesuítas ao longo do século XVII revelam uma apropriação cada vez maior da farmacopéia americana (ervas, resinas e folhas); demonstram também adaptações da terapêutica empregada pelos indígenas, como nos casos dos ferimentos expostos e das otites e conjuntivites decorrentes da varíola.

A medicina presente nas reduções jesuíticas "unió al ingrediente mágico el recurso a los remedios vegetales" (Télles, op. cit., 1993, p. 20), já que, por iniciativa dos missionários e boticários, foram identificadas diversas plantas medicinais e seus usos para incorporação no sistema médico tradicional, com base na medicina humoral "por la cual cada medicamento tenía una cualidad, fria, 
${ }^{12}$ Segundo Téllez (ibidem, p. 22): "Esta patología humoral que pasó a las tierras conquistadas por España, fue curiosamente introducida, más que por médicos o boticarios, por los misioneros y el clero en general, que eran quienes en realidad asistian a los enfermos tanto en los hospitales como en los lugares más remotos, llevando a los indios además de su fe, un nuevo concepto de medicina. Los misioneros, bombres educados en las doctrinas de su tiempo, conocedores de las lenguas y la literatura clásicas y en contacto directo con el pueblo, fueron, pues, el vehículo adecuado para la difusión de la medicina homural". cálida, seca o búmeda y un grado de exponente del uno al cuatro" (idem, ibidem, p. 20). ${ }^{12}$

Apesar de os registros aludirem a uma medicina desprovida de atributos mágicos, relatos como o do padre provincial Andres de Rada, do ano de 1663 - sobre a cura de índios atingidos por uma epidemia pela ingestão de água "tocada con cierta esquela" devem ser levados em conta:

El pueblo de Santa María sufría mucho por cruel peste. ... Y todavía no se veía mengua del contagio, cuando se les ocurrió a los Padres, combatirlo de un modo. Estaba a la mano un libro, recién publicado, del Padre Juan Eusébio (intitulado Opera Parthenical). Leíalo uno de los Padres y en el septimo opúsculo, epist 10, pág 409, encontró que a muchos era saludable remédio água tocada con cierta esquela con la inscripción: In conceptione tua, Virgo immaculata fueste. Ora pro nobis Deum, cujus filium pereriste. ;Cosa maravillosa! Se tomaba el água con aquella esquela, y al instante amaenó aquella calamidad, tanto que nadie fue atacado por la epidemia, y los postrados en cama para esperar su último instante, recobraron sus fuerzas y sanaron (CA [1663-1666], Leonhardt, 1927, p. 102).

Mesmo em obras de caráter médico, como a Opera Parthenical do padre Juan Eusebio, persistem as práticas curativas de caráter mágico. Dentre as possíveis razões para a manutenção e divulgação dessas práticas, ganha relevo a que está associada à mudança de condutas dos indígenas e ao "cambio de sus sentimientos" decorrentes das curas milagrosas, pelas quais "tan supersticiosa gente, se trocó en cristiana y de una fe tenacisima" (Maeder, 1984, p. 80). Buscando exatamente esse efeito - o crescente "aprovechamiento en la fe y costumbres cristianas" (idem, ibidem, p. 147) — os missionários mantiveram o uso de relíquias, da água benta e do sinal da cruz nas reduções, pela crença que os indígenas tinham em sua eficácia.

Apesar dos sucessos obtidos por intermédio da 'magia eclesiástica' e das 'experiências medicinais', "los mesmos misioneros, sabian muy bien sus limitaciones y por eso se preocuparon cuanto antes, traer de Europa hombres especializados en la ciencia médica" (Furlong, apud Echenique, et al., op. cit., p. 258).

A preocupação se materializou na solicitação de envio de médicos, enfermeiros e boticários às missões, encaminhada ao geral da Companhia de Jesus em 1632. Isso explica por quê, apesar das dificuldades em compreender e aceitar as práticas rituais da terapêutica indígena e das restrições à farmacopéia indígena, os herbários e boticários das Missões Jesuíticas seriam admirados por cronistas e historiadores como Azara, Lozano e Guevara.

No século XVIII, caberia aos padres Pedro de Montenegro e Segismundo Asperger a organização de importantes catálogos das ervas medicinais e suas aplicações, sendo esses jesuítas os pioneiros 
${ }^{13}$ De acordo com Arata (1898, pp. 430-1), "Los historiadores del Rio de la Plata (Lozano, Guevara, etc.), los viajeros (Azara, Demersay, Martin de Moussy, etc.) hablan todos com admiración unas veces, y con curiosidad e interes siempre de los Herbarios de las Plantas Medicinales de Misiones hechos por los padres jesuítas y transmitidos manuscritos de reducción en reducción, de convento en convento. ... Los curanderos de la época colonial y aun nuestros médicos viejos, les atribuian grande importancia, a tal punto que se copiaban y volvian a copiar sigilosamente".

\footnotetext{
${ }^{14}$ Bertoni (1927, p. 382) chama a atenção, no entanto, para a importância da farmacopéia indígena nas inovações da medicina moderna: " $\mathrm{La}$ creencia de que el conocimiento de las plantas medicinales de estos países se deba principalmente a los Padres Jesuitas, es bastante generalizada en el público de estos países. Sin embargo, es inexacta. Es indudable que los Jesuitas hicieron mucho; pero fue en el sentido de recoger las informaciones de los Indios, someterlos al crisol de la experiencia, $y$ transmitirlas".
}

na utilização da 'farmacopéia indígena' e suas adaptações feitas à européia. ${ }^{13}$

Ao mencionar uma epidemia de varíola ocorrida em 1719, que teria dizimado 17 mil índios, Pedro Arata (ibidem, p. 443) informa que “... el padre Segismundo Asperger parte com los remedios traidos de Europa y parte com las yerbas medicinales del pais, cuyas virtudes y propiedades conocía muy bien, ... habia libertado de la muerte un gran número de personas".

Também Azara (ibidem, p. 443), referindo-se ao padre Asperger, registra que "el hizo mil ensayos com todas las plantas, que es el medio de hallar específicos, y no el que usan en Europa valiéndose siempre de lo que hay en la botica". ${ }^{14}$

O crescente emprego da farmacopéia indígena na cura de determinadas doenças, não só ampliou as possibilidades de manipulação das curas pelos missionários, como reduziu significativamente o caráter depreciativo atribuído às terapêuticas indígenas. Além disso, ele revela que, conscientes dos efeitos que as curas e a 'boa morte' exerciam sobre os indígenas, os jesuítas não hesitaram em adotar estratégias de apropriação criativa e 'bricoladora' (Certeau, op. cit., pp. 39-40) que garantiam a devoção e a piedade cristãs almejadas.

Para tanto, contribuiu sem dúvida a percepção, tanto dos missionários quanto dos indígenas, de que as doenças resultavam de intervenções sobrenaturais decorrentes de transgressão moral ou religiosa; e que para afastá-las ou garantir a proteção divina, deveriam ser empregados procedimentos terapêuticos e rituais que envolviam cânticos, orações, procissões, exorcismos e práticas mágicas.

Da mesma forma os guarani, valendo-se de seus "modos de percepção e intelecção", buscaram salvaguardar as manifestações tradicionais de sua espiritualidade, por meio de procedimentos de apropriação seletiva e criativa - como fica demonstrado na ressignificação do chorar copioso e dos lamentos fúnebres. Ao viabilizar o projeto reducional, esses procedimentos conformaram de maneira peculiar a sensibilidade religiosa das reduções jesuíticoguaranis. 


\section{REFERÊNCIAS BIBLIOGRÁFICAS}

Arata, Pedro

1898

Arróspide, José Luís 1997

Barran, José Pedro 1990

Bartolomé, Miguel Alberto 1977

Bertoni, Moisés Santiago

1927

Bloch, Marc 1993

1996

Certeau, Michel de 1982

Clastres, Hèléne 1975

1924

Echenique, Nora et al. 1985

Furlong, Guillermo 1962

Garlet, Ivori José 1997

Haubert, Maxime 1987

Leohnardt, Carlos S. J. (org.)

1927

Lévi-Strauss, Claude 1968

Maeder, Ernesto J. A. (org.) 1990

Maeder, Ernesto

J. A. (org.)

1984
'Botanica médica americana. Los herbarios de las misiones del Paraguay'. La Biblioteca, II:VII, Buenos Aires.

Antonio Ruiz de Montoya y las reducciones del Paraguay. Asunción, Centro de Estudios Paraguayos Antonio Guasch.

História de la sensibilidad en el Uruguay. Tomo 1: La Cultura "bárbara": 18900-1860. Montevidéu, Ediciones de la Banda Oriental.

Shamanismo y religión entre los Avá-Katú-Ete. México, Série Antropologia Social, $\mathrm{n}^{\circ}$ 17, Instituto Indigenista Interamericano.

La civilización guarani.

Paraguai, Imprenta y Edición "Ex Sylvis".

Os reis taumaturgos.

São Paulo, Cia. das Letras.

Cartas Ânuas de La Provincia Jesuítica del Paraguay (1641-1643) (CA 1641-3). Resistência, Instituto de Investigaciones Geohistóricas.

Cartas Ânuas de La Provincia del Paraguay, Chile y Tucumán de la Provincia de La Compañia de Jesus (CA). Documentos para la Historia Argentina (DHA), Tomo XX (Iglesia). Buenos Aires.

A escrita da bistória.

Rio de Janeiro, Forense Universitária.

Terra sem mal: o profetismo tupi-guarani.

São Paulo, Brasiliense.

(DHA) Documentos para la Historia Argentina. Tomo XX (Iglesia). Buenos Aires.

'La medicina en las reducciones jesuíticas'. V Simpósio Nacional de Estudos Missioneiros (1983). Anais. Faculdade de Filosofia, Ciências e Letras Dom Bosco, Santa Rosa.

Misiones y sus pueblos de guaranies.

Buenos Aires, Teorema.

Mobilidade Mbyá: história e significação. Porto Alegre, dissertação de mestrado, PUCRS.

'Indios y jesuítas en el Paraguay'.

Suplemento Antropológico, v. XXII, nº 1, Assunção, Universidad Católica.

Cartas Anuas de La Provincia del Paraguay.

Buenos Aires.

Antropologia estrutural.

Buenos Aires, Eudeba.

Cartas Anuas de La Provincia del Paraguay, 1632-1634(CA 1632-4).

Buenos Aires, Academia Nacional de La Historia.

Cartas anuas de la provincia del Paraguay, 1632-1634(CA 1632-4).

Buenos Aires, Fecic. 
1951 (MCA) Manuscritos da Coleção de Angelis. Rio de Janeiro, Biblioteca Nacional, Tomo I (Jesuítas e Bandeirantes no Guairá - 1549-1640).

Meliá, Bartomeu 1986

Métraux, Alfred 1944

Missioneiros 1985

Montoya, Antonio

Ruiz de 1989

Montoya, Antonio Ruiz de 1985

Montoya, Antonio Ruiz de 1876

Pastells, R. P., Pablo, S. J. 1912

Sepp S. J., Pe. Antônio 1980

Susnik, Branislava 1990

Susnik, Branislava 1983

Téllez, Carmen Sánchez 1993

Vara(h), Alfredo 1984

Vianna, Hélio

1970

Viveiros de Castro, Eduardo 1986
El guaraní conquistado y reducido. Ensaios de etnobistoria. Assunção, Biblioteca Paraguaya de Antropologia.

'La causa y el tratamiento mágico de las enfermedades entre los índios de la región tropical sud-americana'. América Indígena, IV:2, pp. 157-64.

Anais. Faculdade de Filosofia, Ciências e Letras Dom Bosco, Santa Rosa, pp. 251-62.

La gran 'Conquista Espiritual' del Paraguay.

Rosario, Equipo Difusor de Estudios de Historia Iberoamericana.

Conquista espiritual.

Porto Alegre, Martins Livreiro.

Vocabulário y tesoro de la lengua guarani. Viena/Paris, Faesy y Frick/

Maisonneuve, 1876. Arte y vocabulário de la lengua guarani.

Viena/Paris, Faesy y Frick/Maisonneuve.

História de la Compañia de Jesús en la Provincia del Paraguay.

Tomo I. Madri, Librería General de Victoriano Suarez.

Viagem às missões jesuíticas e trabalhos apostólicos.

Belo Horizonte/São Paulo, Itatiaia/Edusp.

Guerra. Trânsito. Subsistência (âmbito americano).

Assunção, Manuales del Museo Etnografico Andres Barbero.

Los aborigenes del Paraguay.

V. Ciclo Vital y Estructura Social. Assunção, Museo Etnografico Andres Barbero.

La medicina en las lenguas americanas y filipinas prebispánicas.

s. 1., Producciones Gráficas de la Universidad de Alcalá de Henares.

La construcción guaraní de la realidad - una interpretación psicoanalítica. Assunção, Centro de Estudios Antropológicos, Universidad Católica.

Jesuítas e bandeirantes no Uruguai (1611 - 1758).

MCA IV. Rio de Janeiro, Biblioteca Nacional.

Araweté: os deuses canibais.

Rio de Janeiro, Jorge Zahar.

Recebido para publicação em março de 2003.

Aprovado para publicação em abril de 2004. 